\section{Factor of Safety}

Renato Macciotta

School of Engineering Safety and Risk Management, University of Alberta, Edmonton, AB, Canada

\section{Definition}

The Factor of Safety quantifies the capacity of a system beyond the applied loading or stress regime. For each failure mechanism, the Factor of Safety is calculated as the ratio of available forces preventing failure (including the maximum structural strength) to the forces driving failure (Ryder 1969; Wyllie 2018). It is sometimes referred to as Safety Factor.

\section{Use}

The Factor of Safety is a common approach to address the uncertainties associated with the available strength of structures, the applied loads, and future changes (Ryder 1969). The Factor of Safety evaluates the state of applied stresses to strength of a structure. Values above one indicate a capacity in excess of the applied stresses. A value of one is considered as the state of Limit Equilibrium. The Factor of Safety is also used to specify safety standards for design. In this context, the capacity of the structure is designed in excess of the expected loading as specified by the design Factor of Safety.

The Factor of Safety can be calculated directly from the ratio of resisting forces to driving forces (after Wyllie 2018):

$$
\text { Factor of Safety }=\frac{\sum \text { available forces preventing failure }}{\sum \text { forces driving failure }}
$$

where the available forces preventing failure include the available structure strength and the forces driving failure can include applied and future loads. Another common approach to calculate the Factor of Safety considers the ratio of the available structure strength to the mobilized strength required for a state of Limit Equilibrium (Ryder 1969):

$$
\text { Factor of Safety }=\frac{\text { available or ultimate strength }}{\text { mobilized or working strength }}
$$

In this approach, the forces acting on the structure (external and internal forces) are in equilibrium, and the mobilized strength (strength required for this state of equilibrium) is calculated. This approach can be applied to material friction, cohesion, tensile strength, bearing capacity, among others (see Shear Strength and Bearing Capacity).

Regardless of the approach, calculating the Factor of Safety requires consideration of the available maximum strength (peak strength, residual strength), foreseeable changes of strength with time (decreasing cohesion or friction), and future changes of the applied loading and stress regime.

\section{Cross-References}

\author{
Bearing Capacity \\ $\checkmark$ Failure \\ $>$ Strength \\ Stress
}

\section{References}

Ryder GH (1969) Strength of materials. Palgrave, London. ISBN 978-0333-10928-1

Wyllie DC (2018) Rock slope engineering, 5th edn. CRC Press, Taylor \& Francis Group, Boca Raton. ISBN 9781498786287 